\title{
Corrigendum: Distribution Patterns of DNA N6-Methyladenosine Modification in Non-coding RNA Genes
}

\begin{abstract}
Yu Li ${ }^{1 \dagger}$, Xiao-Ming Zhang ${ }^{2+}$, Mei-Wei Luan ${ }^{1}$, Jian-Feng Xing ${ }^{1}$, Jianguo Chen ${ }^{3 *}$ and Shang-Qian Xie ${ }^{1 *}$

${ }^{1}$ Key Laboratory of Genetics and Germplasm Innovation of Tropical Special Forest Trees and Ornamental Plants (Ministry of Education), Hainan Key Laboratory for Biology of Tropical Ornamental Plant Germplasm, College of Forestry, Hainan University, Haikou, China, ${ }^{2}$ College of Grassland, Resources and Environment, Inner Mongolia Agricultural University, Huhhot, China, ${ }^{3}$ School of Life Sciences, Hubei University, Wuhan, China
\end{abstract}

Keywords: non-coding RNAs, model species, DNA methylation, gene expression, 6mA modification

\section{A Corrigendum on}

Distribution Patterns of DNA N6-Methyladenosine Modification in Non-coding RNA Genes by Li, Y., Zhang, X.-M., Luan, M.-W., Xing, J.-F., Chen, J., and Xie, S.-Q. (2020). Front. Genet. 11:268. doi: 10.3389/fgene.2020.00268

\section{OPEN ACCESS}

Approved by:

Frontiers Editorial Office,

Frontiers Media SA, Switzerland

${ }^{*}$ Correspondence:

Jianguo Chen

chenjg23@hotmail.com

Shang-Qian Xie

sqianxie@foxmail.com

tThese authors have contributed equally to this work and share first authorship

Specialty section: This article was submitted to Computational Genomics,

a section of the journal

Frontiers in Genetics

Received: 20 July 2020

Accepted: 21 July 2020

Published: 25 August 2020

Citation:

Li Y, Zhang X-M, Luan M-W, Xing J-F, Chen J and Xie S-Q (2020)

Corrigendum: Distribution Patterns of

DNA N6-Methyladenosine

Modification in Non-coding RNA

Genes. Front. Genet. 11:904.

doi: 10.3389/fgene.2020.00904
In the original article, there was an error in the abstract. The sentence "Especially, the 6mA-methylated lncRNA genes were expressed significant lower than these genes without methylation in A. thaliana $(p=3.295 \mathrm{e}-4)$, D. melanogaster $(p=3.439 \mathrm{e}-11)$, and $H$. sapiens ( $p=9.087 \mathrm{e}-3$ ) all four species." should be revised to "Especially, the $6 \mathrm{~mA}$-methylated lncRNA genes were expressed significant lower than genes without methylation in $A$. thaliana $(p=3.295 \mathrm{e}-4)$, D. melanogaster $(p=3.439 \mathrm{e}-11)$, and H. sapiens $(p=9.087 \mathrm{e}-3) . "$ A correction has been made in the Abstract.

N6-methyladenosine (6mA) DNA modification played an important role in epigenetic regulation of gene expression. And the aberrational expression of non-coding genes, as important regular elements of gene expression, was related to many diseases. However, the distribution and potential functions of $6 \mathrm{~mA}$ modification in non-coding RNA (ncRNA) genes are still unknown. In this study, we analyzed the $6 \mathrm{~mA}$ distribution of ncRNA genes and compared them with protein-coding genes in four species (Arabidopsis thaliana, Caenorhabditis elegans, Drosophila melanogaster, and Homo sapiens) using single-molecule real-time (SMRT) sequencing data. The results indicated that the consensus motifs of short nucleotides at $6 \mathrm{~mA}$ location were highly conserved in four species, and the non-coding gene was less likely to be methylated compared with protein-coding gene. Especially, the $6 \mathrm{~mA}$-methylated $\operatorname{lncRNA}$ genes were expressed significant lower than genes without methylation in A. thaliana $(p=3.295 \mathrm{e}-4), D$. melanogaster $(p=3.439 \mathrm{e}-11)$, and H. sapiens $(p=9.087 \mathrm{e}-3)$. The detection and distribution profiling of $6 \mathrm{~mA}$ modification in ncRNA regions from four species reveal that $6 \mathrm{~mA}$ modifications may have effects on their expression level.

The authors apologize for this error and state that this does not change the scientific conclusions of the article in any way. The original article has been updated.

Copyright $\odot 2020$ Li, Zhang, Luan, Xing, Chen and Xie. This is an open-access article distributed under the terms of the Creative Commons Attribution License (CC BY). The use, distribution or reproduction in other forums is permitted, provided the original author(s) and the copyright owner(s) are credited and that the original publication in this journal is cited, in accordance with accepted academic practice. No use, distribution or reproduction is permitted which does not comply with these terms. 